\title{
Tachycardia mediated cardiomyopathy: pathophysiology, mechanisms, clinical features and management.
}

\author{
Shuchita Gupta \\ Einstein Institute for Heart and Vascular Health \\ Vincent M. Figueredo, M.D. \\ Thomas Jefferson University
}

Follow this and additional works at: https://jdc.jefferson.edu/cardiologyfp

Part of the Cardiology Commons

Let us know how access to this document benefits you

\section{Recommended Citation}

Gupta, Shuchita and Figueredo, M.D., Vincent M., "Tachycardia mediated cardiomyopathy: pathophysiology, mechanisms, clinical features and management." (2014). Division of Cardiology Faculty Papers. Paper 49.

https://jdc.jefferson.edu/cardiologyfp/49

This Article is brought to you for free and open access by the Jefferson Digital Commons. The Jefferson Digital Commons is a service of Thomas Jefferson University's Center for Teaching and Learning (CTL). The Commons is a showcase for Jefferson books and journals, peer-reviewed scholarly publications, unique historical collections from the University archives, and teaching tools. The Jefferson Digital Commons allows researchers and interested readers anywhere in the world to learn about and keep up to date with Jefferson scholarship. This article has been accepted for inclusion in Division of Cardiology Faculty Papers by an authorized administrator of the Jefferson Digital Commons. For more information, please contact: JeffersonDigitalCommons@jefferson.edu. 
Tachycardia Mediated Cardiomyopathy: Pathophysiology, Mechanisms, Clinical Features and Management

\author{
Shuchita Gupta ${ }^{1}, \mathrm{MD}$, and Vincent M. Figueredo MD ${ }^{1,2}$
}

Einstein Institute for Heart and Vascular Health, Einstein Medical Center, Philadelphia, $\mathrm{PA}^{1}$ and Jefferson Medical College, Philadelphia, $\mathrm{PA}^{2}$

Disclosures: no conflict of interest or funding sources for preparation of this manuscript.

Address correspondence to: Vincent M Figueredo, MD

Einstein Institute for Heart and Vascular Health

5501 Old York Road, 3rd Floor Levy Building

Philadelphia, PA 19141

TEL: $215-456-8991$

FAX: 215-456-3533,

E-mail:figueredov@einstein.edu 


\begin{abstract}
Tachycardia mediated cardiomyopathy (TMC) is a reversible form of dilated cardiomyopathy that can occur with most supraventricular and ventricular arrhythmias. Despite the plethora of literature describing this entity in animal models, as well as humans, it remains poorly understood. Over the last decade, new etiologies of TMC, such as frequent premature ventricular complexes in normal hearts, have been identified. Recent advances in catheter-based ablation therapies, particularly for atrial fibrillation and ventricular arrhythmias, have added a new dimension to the treatment of this condition. This review describes the pathophysiology, proposed mechanisms, clinical features and management in various arrhythmic conditions.
\end{abstract}

KEY WORDS: tachycardia mediated cardiomyopathy, tachycardia-induced heart failure, tachyarrhythmias 


\section{INTRODUCTION}

Incessant tachyarrhythmias can lead to ventricular dilation and systolic dysfunction with signs and symptoms of heart failure (HF). Tachycardia-induced HF was first described in 1913 in a patient with atrial fibrillation (1). Philips and Levine described the relationship between rapid atrial fibrillation and reversible heart failure in 1949 (2). Whipple and colleagues developed an experimental model of tachycardia-mediated cardiomyopathy (TMC) in 1962 (3). Fenelon and colleagues divided TMC in to two types: 1. pure, where tachycardia is the sole mechanism of worsening of LV function; and 2. impure, where tachycardia worsens a pre-existing cardiomyopathy due to a different cause (4).

Over the last 3 decades, multiple papers have described this entity in both animal models and in humans. Despite the plethora of literature, TMC remains a poorly understood entity. This review describes the pathophysiology, clinical features and natural history of TMC.

\section{PATHOPHYSIOLOGY AND PROPOSED MECHANISMS}

SYSTOLIC FUNCTION: In animal models of pacing-induced HF, sustained atrial or ventricular pacing produce severe biventricular systolic dysfunction. This is characterized by increased ventricular filling pressures, decreased cardiac output and increased systemic vascular resistance, without a change in left ventricular (LV) mass $(5,6,7)$. There is loss of intrinsic myocardial contractility with diminished contractile reserve. The marked dilation of ventricles is accompanied by lack of hypertrophy of the left ventricular wall. Microscopic alterations include myocyte loss, myocyte elongation, and effacement of the interface between the basement 
membrane and sarcolemmal surface. The latter leads to decrease force transmission through the ventricular wall $(8,9)$. Depletion of T-tubules occurs in failing ventricular myocytes with rapid pacing, with associated decreases in the density of L-type calcium channels and beta-adrenergic receptors in both surface and T-tubular sarcolemmata. This heterogeneous loss of T-tubules results in abnormal excitation-contraction coupling and may impair contractile efficiency by causing variability in time course of activation of cells (10).

DIASTOLIC FUNCTION: Tachycardia also affects diastolic function by causing incomplete relaxation whereby the myocardium remains in a constant activated state that can be described as a partial or diastolic contracture (11). Calcium extrusion from cardiomyocytes occurs mainly by the sarcolemmal sodium-calcium exchanger. In concert with the sarcoplasmic reticulum (SR), the exchanger restores cytosolic calcium to diastolic levels, thereby causing relaxation. With tachycardia, there is a disproportionate increase in SR calcium content, causing extrusion of calcium in a high calcium environment, which manifests as diastolic contracture (12).

HIGH ENERGY PHOSPHATES: TMC causes depletion of high energy stores in the myocardium due to increased metabolism from persistent tachycardia; this being a reversible process. Tissue adenosine triphosphate (ATP), as well as sodium-potassium ATPase, are significantly decreased in animals with pacing-induced $\operatorname{HF}(13,14)$, while there is an increase in beta-oxidation enzymes and enzymes involved in the Krebs' cycle (15). Selective endothelinreceptor blockade has been shown to attenuate progression of HF by reversing mitochondrial dysfunction (specifically by affecting levels of respiratory complexes V and III involved in the 
Krebs' cycle) in animal models of TMC, thus suggesting the role of endothelin activation in causing ventricular dysfunction (16).

MYOCARDIAL BLOOD FLOW: Chronic supraventricular tachycardia (SVT) in animals has also been shown to result in decreased myocardial blood flow, which normalizes after pacing is terminated $(17,18)$. This may be due to marked elevation of LV end-diastolic pressure (19).

OXIDATIVE STRESS: Oxidative stress has been proposed as a mechanism contributing to TMC in patients with atrial fibrillation (AF). In AF, oxidative modification of ventricular myofibrillar proteins occurs due to peroxynitrite formation, leading to loss of fibrillar function, eventually causing contractile dysfunction $(20,21)$. In an animal study of pacing-induced HF, antioxidant vitamins reduced myocardial oxidative stress, attenuated cardiac dysfunction and prevented myocardial beta-receptor down-regulation and sympathetic nerve terminal dysfunction (22).

ANGIOTENSIN CONVERTING ENZYME: Angiotensin-converting enzyme (ACE) polymorphisms have also been implicated in TMC. Patients with DD genotype (287 base pair deletion in intron 16 of the ACE gene) show exaggerated ACE production in response to any stimulus such as incessant tachycardia. The resultant increase in levels of angiotensin-II causes myocyte elongation, left ventricular enlargement and changes in wall stress $(23,24)$.

NEUROHORMONAL CHANGES: The neurohumoral changes seen in TMC are similar to those in other forms of HF and occur in response to a depressed cardiac output. Activation of the renin- 
angiotensin-aldosterone axis occurs with elevated levels of angiotensin-II, atrial natriuretic peptide (ANP) and endothelin-1, causing abnormal sodium handling. In pacing-induced HF, changes in heart rate, atrial pressure and volume cause increased plasma ANP concentrations, which are attenuated by 1 week due to inability of the atria to be stretched further and because of depletion of atrial ANP concentrations $(25,26)$. As in other disease states, elevated levels of aldosterone may lead to myocardial fibrosis $(27,28)$.

BETA-ADRENERGIC RECEPTORS: There is blunted response to beta-adrenergic stimulation in TMC due to decreased expression of beta-receptors, alterations in beta-receptor transduction including decreased $G$ stimulator protein density (Gs), increased $G$ inhibitory protein density (Gi), and reduced adenylate cyclase activity $(29,30,31)$.

MITRAL REGURGITATION: Similar to other forms of dilated cardiomyopathy, patients with TMC can develop mitral regurgitation (MR) due to mitral annular dilatation and separation of the leaflet hinge points, causing incomplete leaflet coaptation and valve incompetence (32). The saddle shaped mitral annulus in TMC dilates more in the septal-lateral than in the commissurecommissure dimension with flattening of the annulus and decreased contraction occurring in the lateral annulus (33). There is also lengthening of the mitral leaflets due to remodeling near the leaflet edges (34).

RIGHT VENTRICLE: The right ventricle (RV) responds somewhat differently to tachycardia. Unlike the LV where chamber dilation occurs without increase in mass, in the RV, both chamber and myocyte hypertrophy develop. These changes in RV myocardial geometry are associated 
with persistently higher RV myocyte contractile function compared to LV myocytes in TMC (35).

RECOVERY FROM TMC: In animal studies, recovery from TMC is associated with a hypertrophic response of the left ventricle with persistent dilation despite normalization of systolic function (17). This has subsequently been confirmed in clinical studies (36). Diastolic dysfunction can persist even after normalization of systolic function (37). Myocardial blood flow returns to normal, but with decreased coronary flow reserve. Therefore, episodic increases in myocardial oxygen demand in post-supraventricular tachycardia hearts (e.g., with recurrence of tachycardia) can result in reduced myocardial blood flow and reduced LV function (17).

In a study comparing patients with TMC due to SVT with those with idiopathic dilated cardiomyopathy (DCMP), significant improvement in LV ejection fraction was noted in the former group with rate control. LV dimensions and mass and volume indices were smaller in the TMC group than DCMP group. A lower LV end-diastolic dimension was the only significant predictor of recovery in multivariable analysis (38).

In a recent study of 18 patients with TMC due to focal atrial tachycardia that had an improvement in ejection fraction within 3 months of radiofrequency ablation, subtle differences in LV structure and function were noted at 5 years, with larger LV dimensions, lower EF, decreased myocardial strain and twist rate and evidence of diffuse myocardial fibrosis on late gadolinium enhanced cardiac MRI, suggesting incomplete recovery (39). 


\section{TACHYCARDIA-MEDIATED ATRIAL CARDIOMYOPATHY (TMAC)}

Atrial tachycardia and atrial fibrillation (AF) have been shown to cause contractile dysfunction of the atria. In addition, cardioversion of AF to sinus rhythm causes atrial mechanical dysfunction, the degree of which depends upon the duration of preceding AF (40,41). Rapid atrial pacing affects both atrial systolic and diastolic function characterized by absent atrial booster pump function, increased atrial chamber stiffness, enhanced atrial conduit function, and atrial enlargement (42). Abnormalities in calcium handling and impaired systolic transient calcium currents due to downregulation or dysfunction of the L-type calcium channel and altered myofilament function (associated with abnormal myosin and myosin-associated protein phosphorylation) have been proposed as mechanisms of the atrial cardiomyopathy $(43,44,45,46)$. Upregulation of the sodium-calcium exchanger worsens calcium depletion by causing its efflux from atrial cardiomyocytes of AF patients, thus contributing to the atrial contractile dysfunction post cardioversion. Unlike its ventricular counterpart, beta-adrenergic receptor desentization does not contribute to TMAC (47).

\section{INCIDENCE AND PREDISPOSING FACTORS}

The incidence of TCM is variable depending upon the type of tachycardia. In a study of 625 patients referred for radiofrequency ablation of tachyarrhythmias, TCM was found in 17 patients (2.7\%) (48). The incidence for specific arrhythmias has been described as ranging from $10 \%$ in patients with focal atrial tachycardia (49), to $20-50 \%$ in patients with permanent junctional reciprocating tachycardia $(\mathrm{PJRT})(50,51)$ and $25 \%$ in patients with incessant atrial flutter $(52)$. The incidence of TCM in atrial fibrillation and ventricular tachycardia has not been described adequately in literature. Younger patients, males, those with slower tachycardias, and incessant 
tachycardias are more prone to develop TMC according to one study (49). Those with rapid paroxysmal tachycardias are more likely to be symptomatic and be diagnosed sooner than those with slower, but incessant tachycardias In patients with atrial fibrillation (AF), the irregularity of R-R interval may itself predispose to cardiomyopathy and heart failure, apart from the effects of rapid heart rates $(50)$.

\section{DIAGNOSIS AND MANAGEMENT}

There are no established diagnostic criteria for TMC. However, in a patient presenting with new onset LV dysfunction and a chronic or recurrent tachycardia with heart rate over 100 beats per minute, the diagnosis of TMC may be suggested by the following once ischemic cardiomyopathy is ruled out:

1. No other cause of non-ischemic cardiomyopathy found (eg. hypertension, alcohol or drug use, stress etc.)

2. Absence of LVH

3. Relatively normal LV dimensions ( $\mathrm{LV}$ end-diastolic dimension $<5.5 \mathrm{~cm}$ )

4. Recovery of LV function after control of tachycardia (by rate control, cardioversion or radiofrequency ablation) within one to six months.

5. Rapid decline in LVEF following recurrence of tachycardia in a patient with recovered LV function after control of tachycardia previously.

In addition, there is evidence that the ratio of N-terminal-pro brain natriuretic peptide (NT-proBNP) concentration in patients with suspected TMC before and after control of tachycardia may help in distinguishing these patients from those with structural heart disease. In one study, the level of NT-pro-BNP was elevated in patients with SVT with depressed LV function and 
declined after cardioversion within a week (51). Thus serial measurements of NT-pro-BNP may be useful in supportive diagnosis of TMC, though this requires further exploration.

Initial management of TMC comprises evidence-based treatment for HF with reduced LVEF, including angiotensin converting enzyme inhibitors and beta-blockers. Treatment of tachycardia involves control of ventricular response with rate-controlling drugs, use of anti-arrhythmic drugs, direct-current cardioversion or catheter ablation of the tachyarrhythmia.

\section{TMC AND RECURRENT TACHYCARDIA}

TMC usually resolves with treatment of tachycardia. The time course of improvement in LVEF is variable. However, recurrence of tachycardia can cause a precipitous decline in LVEF due to persistent ultrastructural changes. Nerheim et al (52) described a series of 24 patients with TMC out of which 5 had recurrent tachycardia causing marked decline in LVEF. Three of their patients died suddenly and unexpectedly. This suggests that patients may be at increased risk for sudden cardiac death following improvement of TMC, which could be due to persistent myocardial fibrosis as demonstrated on cardiac MR (39).

\section{ARRHYTHMIAS ASSOCIATED WITH TMC}

A list of tachyarrhythmias that have been associated with TMC is shown in Table 1. Both supraventricular and ventricular arrhythmias can cause TMC, as can sinus tachycardia, particularly in association with thyrotoxicosis. We present some common arrhythmias associated with TMC and salient features in their management. 
ATRIAL FIBRILLATION (AF): AF is the most common sustained arrhythmia, encountered in $1.5 \%$ of the population (53). AF compromises LV systolic function through poor rate control (usually sustained ventricular rates above 120 beats per minute), irregularity of ventricular response, and loss of atrial systolic activity. Loss of atrioventricular (AV) synchrony is associated with impaired diastolic filling, reduced stroke volume, and elevated diastolic atrial pressure, resulting in an approximately $20 \%$ reduction in cardiac output (54). AF and HF thus form a vicious cycle whereby one worsens the other.

Although conversion of a patient back to sinus rhythm appears an attractive therapeutic goal, in both AFFIRM (AF Follow-Up Investigation of Rhythm Management) and RACE (Rate Control Versus Electrical Cardioversion for Persistent AF) trials, rhythm control strategy provided no benefit and actually showed a trend toward harm in the general population of patients compared with rate control $(55,56)$. This was due, at least in part, to toxicity of the anti-arrhythmic drugs, along with an inability to maintain SR in most patients. These trials, however, did not address the issue of TMC.

Although rate control was found to be superior to rhythm control in AFFIRM and RACE, subsequent analyses suggested a benefit of maintaining sinus rhythm, which was completely offset by the toxicity of anti-arrhythmic drugs $(57,58)$. One technique of achieving sinus rhythm without anti-arrhythmic drugs would be curative catheter ablation. In most cases, paroxysmal AF is initiated by triggers located within pulmonary vein musculature. Circumferential ablation to isolate this musculature can eliminate paroxysmal AF in selected populations. Because of the problem of recurrent pulmonary vein connections, more than one 
procedure is needed in approximately $30 \%$ of patients, and new technologies are being developed to reduce this requirement (59). In a study of patients undergoing pulmonary vein isolation, $18 \%$ had depressed LVEF $(<50 \%)$. The mean LVEF improved significantly in these patients following ablation, the improvement being more marked in those who achieved successful AF control (Figure 1). Of note, the degree of AF control in these patients was similar to that in patients with normal LV function, but they required more procedures (60).

The Pulmonary Vein Antrum Isolation versus AV Node Ablation with Bi-Ventricular Pacing for Treatment of Atrial Fibrillation in Patients with Congestive Heart Failure (PABA-CHF) study was a multicenter, randomized, controlled trial comparing pulmonary vein isolation with atrioventricular-node biventricular pacing in patients with symptomatic AF, NYHA class II or III $\mathrm{HF}$ and LVEF $\leq 40 \%$ (61). Patients who underwent pulmonary vein isolation demonstrated greater improvement in LVEF, six-minute walk distance and quality of life parameters at 6 months compared to the latter group. However, long term superiority of one strategy over the other has not been established as this was a relatively short follow-up period.

Catheter ablation is now being explored as first line therapy in persistent AF. A recent randomized, open label, blinded-endpoint clinical trial involving 52 patients with symptomatic $\mathrm{HF}$, persistent $\mathrm{AF}$ and $\mathrm{LVEF} \leq 35 \%$, compared catheter ablation with rate control (62). Catheter ablation significantly improved peak oxygen consumption (VO2), Minnesota Living with Heart Failure Questionnaire score and brain-natriuretic peptide (BNP) values at 12 months, with a trend towards increase in LVEF and six-minute walk distance. In this study, 96\% of patients in the rate control group had adequate rate control at 12 months, and maintenance of SR was 
achieved in $92 \%$ of patients in ablation group. This study suggests that rhythm control with successful ablation of AF may have an overall advantage over adequate rate control for physiologic improvement, though longer follow-up is necessary.

An extreme form of rate control strategy is atrioventricular (AV) nodal ablation with implantation of a permanent pacemaker, the "ablate and pace strategy". This procedure's use is reserved largely for older patients with significant co-morbidities. It does result in progression of paroxysmal AF to permanent $\mathrm{AF}$ in up to $32 \%$ of patients within 2 months. Also, continuous right ventricular pacing itself has deletrious effects on LV systolic function due to LV dyssynchrony (63). However, AV nodal ablation may be beneficial if simultaneous cardiac resynchronization therapy (CRT) is performed in patients meeting CRT criteria. In a systematic review of 3 studies, AV nodal ablation was associated with a substantial reduction in all-cause mortality and cardiovascular mortality, with improvements in New York Heart Association functional class when compared with medical therapy in AF patients receiving CRT (64).

TMC RELATED TO OTHER SUPRAVENTRICULAR ARRHYTHMIAS: TMC can develop with any form of frequent paroxysmal or incessant supraventricular tachycardia. Patients with chronic atrial flutter have been shown to develop TMC, which improves after radiofrequency ablation $(65,66)$. In a study of 345 patients undergoing catheter ablation for focal atrial tachycardia, TMC was seen in $10 \%$ of cases (49). Patients with TMC were younger, more often male, had mostly incessant tachycardia, and had a longer tachycardia cycle length and slower ventricular rate compared to those who did not have TMC. Foci of atrial tachycardia were mostly found either in the atrial appendages or the pulmonary veins in patients with TMC. 
Normalization of LVEF was seen in $97 \%$ of patients at a mean follow-up of 3 months. Cruz et al. (67) described TMC resulting from incessant tachycardia due to an accessory pathway with a long retrograde conduction time, which was reversible following surgical ablation of the accessory pathway. Children may develop TMC with ectopic atrial tachycardia or permanent junctional reciprocating tachycardia, which is reversible following radiofrequency ablation $(68,69,70,71)$.

TMC RELATED TO VENTRICULAR ARRHYTHMIAS: Ventricular arrhythmias that can cause TMC include ventricular tachycardia (VT) in patients with structurally normal hearts and frequent, monomorphic premature ventricular contractions (PVC) (72). Multiple case reports and case series have described TMC in association with idiopathic right ventricular outflow tract VT (RVOT-VT) $(73,74)$ and idiopathic left ventricular tachycardia (75), where the cardiomyopathy was reversible after successful radiofrequency ablation. In a study of 249 patients with idiopathic repetitive monomorphic PVCs and/or VT, 9\% had TMC, and 29\% of these were asymptomatic (76). All patients had improvement in LVEF following treatment with either anti-arrhythmics or radiofrequency ablation. The predictors for development of TMC identified were male gender, absence of symptoms, PVC burden of $\geq 16 \%$, persistence of PVCs throughout the day, and the presence of repetitive monomorphic VT. In another study by the same group, late gadolinium enhancement on cardiac magnetic resonance imaging was seen in patients with TMC who did not recover their LV systolic function after treatment of the index VT (77). Late gadolinium enhancement on cardiac magnetic resonance imaging is indicative of scar, thus these patients probably did not have pure TMC. 
PVCs have been detected in $1 \%$ of subjects on standard 12-lead electrocardiography and between 40 and $75 \%$ of subjects on 24 to 48 hour ambulatory electrocardiographic monitoring in the normal population (78). PVCs were thought to be benign. However, in the last decade, cardiomyopathy due to frequent PVCs in otherwise healthy hearts is now recognized. In the Atherosclerosis Risk in Communities (ARIC) study, association of frequent PVCs with HF incidence in a population-based cohort, free of HF and coronary heart disease at baseline, was studied (79). Over a follow-up period of 15 years, the incidence of HF in subjects with $>1$ PVC on a 2 minute electrocardiographic rhythm strip was significantly higher than in those with no PVCs (hazard ratio 1.71, after adjusting for variables including coronary artery disease) (Figure 2).

The concept of PVC-induced cardiomyopathy was described by Duffee et al. (80) who noted that pharmacological suppression of PVCs in patients with presumed idiopathic dilated cardiomyopathy improved LV systolic dysfunction. The frequency of PVCs appears to correlate with LV dysfunction. Frequent PVCs have been variably defined as $>10,000$ PVCs in 24 hours (81), $>20,000$ PVCs in 24 hours (82) or $>24 \%$ of total heart beats (83). Approximately a third of patients with frequent PVCs develop cardiomyopathy. Two-thirds of PVCs arise from outflow tracts, particularly the RVOT, and one-third have various ventricular origins: free walls, LV fascicles, septum and papillary muscles.

Mechanisms postulated for PVC-induced TMC include a true rate-related cardiomyopathy due to higher average heart rates in patients with frequent PVCs with a short coupling interval, LV dyssynchrony during PVCs and chronic effects of extra-systolic potentiation leading to increases 
in intracellular calcium and myocardial oxygen consumption (84). Ventricular dyssynchrony causes reduced global cardiac mechanical efficiency, asymmetrically increased wall thickness in the late-activated regions, altered myocardial blood flow, and local changes in myocardial protein expression, thus causing LV dilation and dysfunction in a manner similar to chronic RV pacing (85). Identified predictors of cardiomyopathy in patients with frequent PVCs include (besides PVC burden) wider PVCs, PVCs of epicardial origin (86), presence of interpolated PVCs (87) and presence of retrograde P waves (88). The threshold burden of PVCs associated with reduced LVEF may be lower for right as compared to left ventricular PVCs (89).

A therapeutic medical trial for 3 months or catheter ablation should be considered for patients with presumed PVC-induced cardiomyopathy. Beta-blockers, amiodarone and dofetilide can all suppress PVCs and can be safely used in patients with LV dysfunction $(90,91,92)$. Catheter ablation has emerged as an increasing popular option for these patients as the safety and efficacy profiles of the procedure have improved. Several studies have documented an improvement in LVEF following PVC ablation in nearly all patients along with significant reductions in LV enddiastolic dimensions of between 2 and $8 \mathrm{~mm}$, mitral regurgitation by 75\%, and New York Heart Association functional class by nearly 1 class $(93,94,95)$. Significant improvement in radial, circumferential, and longitudinal strain after catheter ablation in patients with frequent PVCs and preserved LVEF has also been shown (96). Short-term ablation success rates of between $70 \%$ and $90 \%$ have been reported $(97,98)$. Early improvement in LVEF after ablation ( $>25 \%$ increase at 1 week) was shown to predict complete recovery of LV systolic function in one study (98). 
TMC IN THYROTOXICOSIS: Approximately $6 \%$ of patients with thyrotoxicosis develop HF symptoms, but only $1 \%$ develop dilated cardiomyopathy with reduced LV systolic function. This can occur with sinus tachycardia or atrial fibrillation with a rapid ventricular response. HF resulting from thyrotoxicosis is due to a tachycardia-mediated mechanism leading to increased levels of cytosolic calcium during diastole with reduced ventricular contractility and diastolic dysfunction (99). Most patients recover their LV systolic function after control of tachycardia and achievement of a euthyroid state. Patients who develop TMC have lower levels of serum thyroxine than those who do not, which reflects a higher incidence of subclinical hyperthyroidism in these patients (100).

\section{FUTURE DIRECTIONS}

While there is an abundance of animal studies on TMC, studies in humans are remarkably limited. Future research needs to be directed towards studying the pathophysiology of this entity in human beings, with particular reference to predisposing factors. It is likely that genetic factors (such as ACE polymorphism which has already been described) will be found to play a significant role in the development of TMC. Emerging data suggest that the presence of fibrosis on cardiac MR imaging may identify patients with TMC who are less likely to recover their LV function. These patients may be at elevated risk of recurrence of TMC as well as sudden cardiac death, which is a hypothesis that needs further exploration. In addition, with reference to atrial fibrillation, it remains to be determined whether conversion to sinus rhythm with catheter ablation has long-term superiority over rate control strategy in certain patients with TMC. 


\section{CONCLUSIONS}

TMC is a form of dilated cardiomyopathy which can be reversible with treatment of the underlying tachycardia. TMC patients who gain return of LV function do remain at an elevated risk for recurrence and for sudden cardiac death, hence long-term follow-up of these patients is necessary. 


\section{REFERENCES}

1. Gossage AM, Braxton Hicks JA. On auricular fibrillation. QJM 1913;6:435-440.

2. Phillips E, Levine SA. Auricular fibrillation without other evidence of heart disease: a cause of reversible heart failure. Am J Med 1949;7:478-89.

3. Whipple GH, Sheffield LT, Woodman EG. Reversible congestive heart failure due to chronic rapid stimulation of the normal heart. Pro N Engl Cardiovasc Soc 1962;20:39-40.

4. Fenelon G, Wijns Andries E, Brugada P. Tachycardiomyopathy. Mechanisms and clinical implications. Pacing Clin Electrophysiol 1996;16:95-106

5. Spinale FG, Hendrick DA, Crawford FA, Smith AC, Hamada Y, Carabello BA. Chronic supraventricular tachycardia causes ventricular dysfunction and subendocardial injury in swine. Am J Physiol 1990;259:218-29.

6. Chow E, Woodard JC, Farrar DJ. Rapid ventricular pacing in pigs: an experimental model of congestive heart failure. Am J Physiol 1990;258:1603-5.

7. Shinbane JS, Wood MA, Jensen M, Ellenbogen KA et al. Tachycardia-Induced Cardiomyopathy: A Review of Animal Models and Clinical Studies. J Am Coll Cardiol 1997;29:709-15.

8. Zellner JL, Spinale FG, Eble DM, Hewett KW et al. Alterations in myocyte shape and basement membrane attachment with tachycardia-induced heart failure. Circ Res 1991;69:590600.

9. Kajstura J, Zhang X, Liu Y, Szoke E et al. The cellular basis of pacing-induced dilated cardiomyopathy. Myocyte cell loss and myocyte cellular reactive hypertrophy. Circulation 1995;92(8):2306-2317. 
10. Balijepalli R, Lokuta AJ, Maertz NA, Buck JM et al. Depletion of T-tubules and specific subcellular changes in sarcolemmal proteins in tachycardia-induced heart failure. Cardiovasc Res 2003; 59(1): 67-77.

11. Langer GA. Heart: Excitation-contraction coupling. Annu Rev Physiol 1973;35:55-86.

12. Selby DE, Palmer BM, LeWinter MM, Meyer M. Tachycardia-Induced Diastolic

Dysfunction and Resting Tone in Myocardium From Patients With a Normal Ejection Fraction. J Am Coll Cardiol 2011;58(2):147-154.

13. Moe GW, Montgomery C, Howard RJ, et al. Left ventricular myocardial blood flow, metabolism and effects of treatment with enalapril: Further insights into the mechanisms of canine experimental pacing-induced heart failure. J Lab Clin Med 1993; 131:294-302.

14. Spinale FG, Clayton C, Tanaka R, et al. Myocardial Na, K-ATPase in tachycardia induced cardiomyopathy. J Mol Cell Cardiol. 1992;24:277-289.

15. O'Brien PJ, Ianuzzo CD, Moe GW, et al. Rapid ventricular pacing of dogs to heart failure: Biochemical and physiological studies. Can J Physiol Pharmacol. 1990;68:34-45. 16. Marin-Garcia J, Goldenthal MJ, Moe GW. Selective endothelin receptor blockade reverses mitochondrial dysfunction in canine heart failure. J Card Fail 2002; 8(5):326-332. 17. Moe GW, Armstrong P. Pacing-induced heart failure: a model to study the mechanism of disease progression and novel therapy in heart failure. Cardiovasc Res 1999; 42(3): 591-599. 18. Spinale FG, Tanaka R, Crawford FA, Zile MR. Changes in myocardial blood flow during development of and recovery from tachycardia-induced cardiomyopathy. Circulation 1992;85: 717-729. 
19. Shannon RP, Komamura K, Shen YT, Bishop SP et al. Impaired regional subendocardial coronary flow reserve in conscious dogs with pacing-induced heart failure. Am J Physiol 1993;265(3.2):801-809.

20. Mihm MJ, Coyle C, Schanbacher BL et al. Peroxynitrite induced nitration and inactivation of myofibrillar creatine kinase in experimental heart failure. Cardiovasc Res 2001; 49: 798-807.

21. Mihm MJ, Yu F, Carnes CA, Reiser PJ, McCarthy PM et al. Impaired myofibrillar energetics and oxidative injury during human atrial fibrillation. Circulation 2001;104(2):174180.

22. Shite J, Qin F, Mao W, Kawai $\mathrm{H}$ et al. Antioxidant vitamins attenuate oxidative stress and cardiac dysfunction in tachycardia-induced cardiomyopathy. J Am Coll Cardiol 2001;38(6):1734-1740.

23. Rigat H, Hubert C, Alheno-Gelas F, Cambien F et al. An insertion/ deletion polymorphism in the angiotensin-I converting enzyme accounting for half the variance of serum enzyme levels. J Clin Invest 1990;86:1343-1346.

24. Deshmukh PM, Krishnamani R, Romanyshyn M, Johnson AK et al. Association of angiotensin converting enzyme gene polymorphism with tachycardia cardiomyopathy. Int J Mol Med 2004;13(3):455-8.

25. Moe GW, Grima EA, Wong NL, Howard RJ, Armstrong PW. Dual natriuretic peptide system in experimental heart failure. J Am Coll Cardiol 1993; 22(3):891-898.

26. Moe GW, Angus C, Howard RJ, De Bold AJ, Armstrong PW. Pathophysiological role of changing atrial size and pressure in modulation of atrial natriuretic factor during evolving experimental heart failure. Cardiovasc Res 1990; 24(7):570-577. 
27. Fullerton M J, Funder JW. Aldosterone and cardiac fibrosis: in vitro studies. Cardiovasc Res 1994; 28: 1863-1867.

28. Young MJ, Lam EY, Rickard AJ. Mineralocorticoid receptor activation and cardiac fibrosis. Clin Sci (Lond) 2007; 112(9):467-475.

29. Burchell SA, Spinale FG, Crawford FA, Tanaka R et al. Effects of chronic tachycardiainduced cardiomyopathy on the beta-adrenergic receptor system. J Thorac Cardiovasc Surg 1992;104(4):1006-1012.

30. Tanaka R, Fulbright BM, Mukherjee R, Burchell SA et al. The cellular basis for the blunted response to beta-adrenergic stimulation in supraventricular tachycardia-induced cardiomyopathy. J Mol Cell Cardiol 1993;25(10):1215-1233.

31. Spinale FG, Tempel GE, Mukherjee R, Eble DM et al. Cellular and molecular alterations in the beta adrenergic system with cardiomyopathy induced by tachycardia. Cardiovasc Res 1994;28(8):1243-1250.

32. Timek TA, Dagum P, Lai DT, Liang D et al. Pathogenesis of Mitral Regurgitation in Tachycardia-Induced Cardiomyopathy. Circulation 2001; 104: I-47-I-53.

33. Timek TA, Dagum P, Lai DT, Liang D et al. Tachycardia-induced cardiomyopathy in the ovine heart: mitral annular dynamic three-dimensional geometry. J Thorac Cardiovasc Surg $2003 ; 125(2): 315-324$.

34. Timek TA, Lai DT, Dagum P, Liang D et al. Mitral Leaflet Remodeling in Dilated Cardiomyopathy. Circulation 2006; 114: I-518-I-523.

35. Jeong YH, Choi KJ, Song JM, Hwang ES et al. Diagnostic approach and treatment strategy in tachycardia-induced cardiomyopathy. Clin Cardiol 2008;31(4):172-178. 
36. McMahon WS, Mukherjee R, Gillette PC, Crawford FA et al. Right and left ventricular geometry and myocyte contractile processes with dilated cardiomyopathy: myocyte growth and beta-adrenergic responsiveness. Cardiovasc Res 1996; 31(2): 314-323.

37. Dandamudi G, Rampurwala AY, Mahenthiran J, Miller JM et al. Persistent left ventricular dilatation in tachycardia-induced cardiomyopathy patients after appropriate treatment and normalization of ejection fraction. Heart Rhythm 2008;5 (8):1111-1114.

38. Tomita M, Spinale FG, Crawford FA, Zile MR. Changes in left ventricular volume, mass, and function during the development and regression of supraventricular tachycardia-induced cardiomyopathy. Disparity between recovery of systolic versus diastolic function. Circulation 1991; 83(2):635-44.

39. Ling L, Kalman JM, Ellims AH, et al. Diffuse ventricular fibrosis is a late outcome of tachycardia-mediated cardiomyopathy after successful ablation. Circ Arrhythm Electrophysiol 2013;6:697-704.

40. Grimm RA, Stewart WJ, Arheart K, et al. Left atrial appendage "stunning" after electrical cardioversion of atrial flutter: an attenuated response compared with atrial fibrillation as the mechanism for lower susceptibility to thromboembolic events. J Am Coll Cardiol 1997;29: 582589.

41. Sanders P, Morton JB, Kistler PM, Vohra JK et al. Reversal of Atrial Mechanical Dysfunction After Cardioversion of Atrial Fibrillation: Implications for the Mechanisms of Tachycardia-Mediated Atrial Cardiomyopathy. Circulation 2003; 108: 1976-1984.

42. Hoit BD, Takeishi Y, Cox MJ, Gabel M et al. Remodeling of the left atrium in pacinginduced atrial cardiomyopathy. Mol Cell Biochem 2002; 238(1-2):145-50. 
43. Sun H, Gaspo R, Leblanc N, Nattel S. Cellular mechanisms of atrial contractile dysfunction caused by sustained atrial tachycardia. Circulation 1998; 98(7):719-727.

44. Schotten U, Ausma J, Stellbrink C et al. Cellular mechanisms of depressed atrial contractility in patients with chronic atrial fibrillation. Circulation 2001; 103:691-698.

45. Wakili R, Yeh Y, Yan Qi X, Greiser M et al. Multiple Potential Molecular Contributors to Atrial Hypocontractility Caused by Atrial Tachycardia Remodeling in Dogs. Circ Arrhythm Electrophysiol. 2010; 3:530-541.

46. Zhong JQ, Zhang W, Li Y, Zhong M et al. Changes in metalloproteinase and tissue inhibitor of metalloproteinase during tachycardia-induced cardiomyopathy by rapid atrial pacing in dogs. Cardiology 2006; 106(1):22-8.

47. Schotten U, Greiser M, Benke D, Buerkel K et al. Atrial fibrillation-induced atrial contractile dysfunction: a tachycardiomyopathy of a different sort. Cardiovascular Research 2002; 53:192-201.

48. Donghua Z, Jian P, Zhongbo X, et al. Reversal of cardiomyopathy in patients with congestive heart failure secondary to tachycardia. J Interv Card Electrophysiol 2013;36:27-32.

49. Medi C, Kalman JM, Haqqani H et al. Tachycardia-Mediated Cardiomyopathy Secondary to Focal Atrial Tachycardia: Long-Term Outcome After Catheter Ablation. J Am Coll Cardiol 2009; 53(19):1791-1797.

50. Clark DM, Plumb VJ, Epstein AE, Kay GN. Hemodynamic effects of an irregular sequence of ventricular cycle lengths during atrial fibrillation. J Am Coll Cardiol 1997 ;30(4):1039-1045.

51. Nia AM, Gassanov N, Dahlem KM, et al. Diagnostic accuracy of NT-proBNP ratio (BNP-R) for early diagnosis of tachycardia-mediated cardiomyopathy: a pilot study. Clin Res Cardiol. 2011;100(10):887-896. 
52. Nerheim P, Birger-Botkin S, Piracha L, Olshanky B. Heart Failure and Sudden Death in Patients With Tachycardia-Induced Cardiomyopathy and Recurrent Tachycardia. Circulation 2004;110:247-252.

53. Go AS, Hylek EM, Phillips KA, et al. Prevalence of diagnosed atrial fibrillation in adults. National implications for rhythm management and stroke prevention: the AnTicoagulation and Risk Factors In Atrial Fibrillation (ATRIA) Study. JAMA 2001; 285: $2370 \mathrm{e} 5$.

54. Naito M, David D, Michelson EL, et al. The hemodynamic consequences of cardiac arrhythmias: evaluation of the relative roles of abnormal atrioventricular sequencing, irregularity of ventricular rhythm and atrial fibrillation in a canine model. Am Heart J 1983;106: $284 \mathrm{e} 91$. 55. Wyse DG, Waldo AL, DiMarco JP, Domanski MJ et al. A comparison of rate control and rhythm control in patients with atrial fibrillation. N Engl J Med 2002;347(23):1825-1833.

56. Van Gelder IC, Hagens VE, Bosker HA et al A comparison of rate control and rhythm control in patients with recurrent persistent atrial fibrillation. N Engl J Med2002;347:1834-40. 57. Corley SD, Epstein AE, DiMarco JP, Domanski MJ et al. Relationships between sinus rhythm, treatment, and survival in the Atrial Fibrillation Follow-Up Investigation of Rhythm Management (AFFIRM) Study. Circulation 2004;109:1509-1513.

58. Pederson OD, Bagger H, Keller N, Marchant B et al. Efficacy of Dofetilide in the Treatment of Atrial Fibrillation-Flutter in Patients With Reduced Left Ventricular Function. Circulation 2001; 104:292-296.

59. Lee G, Sanders P, Kalman JM. Catheter ablation of atrial arrhythmias: state of the art. Lancet 2012; 380(9852):1509-1519. 
60. Gentlesk PJ, Sauer WH, Gerstenfeld EP, Lin D et al. Reversal of left ventricular dysfunction following ablation of atrial fibrillation. J Cardiovasc Electrophysiol 2007; 18(1):914.

61. Khan MN, Jaïs P, Cummings J, Di Biase L et al. Pulmonary-vein isolation for atrial fibrillation in patients with heart failure. N Engl J Med 2008; 359: 1778-85.

62. Jones DG, Haldar SK, Hussain W, Sharma R et al. A Randomized Trial to Assess Catheter Ablation versus Rate Control in the Management of Persistent Atrial Fibrillation in Heart Failure (ARC-HF). J Am Coll Cardiol 2013; 61 (18): 1894-1903.

63. Ozcan C, Jahangir A, Friedman PA, Munger TM, et al. Significant effects of atrioventricular node ablation and pacemaker implantation on left ventricular function and longterm survival in patients with atrial fibrillation and left ventricular dysfunction. Am J Cardiol 2003; 92(1): 33-37.

64. Gasparini M, Galimberti P. AV Junction Ablation in Heart Failure Patients With Atrial Fibrillation Treated With Cardiac Resynchronization Therapy: The Picture Is Now Clear! J Am Coll Cardiol 2012; 59(8):727-729.

65. Luchsinger J, Steinberg J. Resolution of cardiomyopathy after ablation of atrial flutter. J Am Coll Cardiol 1998; 32(1): 205-210.

66. Pizzale S, Lemery R, Green MS, et al. Frequency and predictors of tachycardia-induced cardiomyopathy in patients with persistent atrial flutter. Can J Cardiol 2009;25(8):469-472.

67. Cruz FE, Cheriex EC, Smeets JL et al. Reversibility of tachycardia induced cardiomyopathy after cure of incessant supraventricular tachycardia. J Am Coll Cardiol 1990; 16: 739-744. 
68. Gaita F, Haissaguerre M, Giustetto C, et al. Catheter ablation of permanent junctional reciprocating tachycardia with radiofrequency current. J Am Coll Cardiol 1995;25(3):648-654. 69. Dorostkar PC, Silka MJ, Morady F, Dick M 2nd. Clinical course of persistent junctional reciprocating tachycardia. J Am Coll Cardiol 1999;33(2):366-75.

70. Giovanni JV, Dindar A, Griffith MJ et al. Recovery pattern of left ventricular dysfunction following radiofrequency ablation of incessant supraventricular tachycardia in infants and children. Heart 1998; 79: 588-592.

71. Sanchez C, Benito F, Moreno F et al. Reversibility of tachycardia-induced cardiomyopathy after radiofrequency ablation of incessant supraventricular tachycardia in infants. Br Heart J 1995;74: 332-333.

72. Badhwar N, Scheinman MM. Idiopathic ventricular tachycardia: Diagnosis and management. Curr Probl Cardiol 2007; 32:7-43.

73. Vijgen J, Hill P, Biblo LA, Carlson MD. Tachycardia-induced cardiomyopathy secondary to right ventricular outflow tract ventricular tachycardia: improvement of left ventricular systolic function after radiofrequency catheter ablation of the arrhythmia. J Cardiovasc Electrophysiol 1997; 8(4):445-50.

74. Grimm W, Menz V, Hoffmann J, Maisch B. Reversal of tachycardia induced cardiomyopathy following ablation of repetitive monomorphic right ventricular outflow tract tachycardia. Pacing Clin Electrophysiol 2001; 24(2):166-71.

75. Castro-Rodriguez J, Verbeet T, Morissens M, Lomas O et al. Complicated Forms of Tachycardia-Mediated Cardiomyopathy Associated with Idiopathic Left Ventricular Tachycardia. Pacing Clin Electrophysiol 2011; 34:e52-e55. 
76. Hasdemir C, Ulucan C, Yavuzgil O, Yuksel A et al. Tachycardia-Induced Cardiomyopathy in PatientsWith Idiopathic Ventricular Arrhythmias: The Incidence, Clinical and Electrophysiologic Characteristics, and the Predictors. J Cardiovasc Electrophysiol 2011; 22: 663-668.

77. Hasdemir C, Yuksel A, Camli D, Kartal Y et al. Late Gadolinium Enhancement CMR in Patients with Tachycardia-Induced Cardiomyopathy Caused by Idiopathic Ventricular Arrhythmias. Pacing Clin Electrophysiol 2012; 35: 465-470.

78. Ng GA. Treating patients with ventricular ectopic beats. Heart 2006; 92:1707-1712.

79. Agarwal SK, Simpson RJ Jr, Rautaharju P, Alonso A et al. Relation of Ventricular Premature Complexes to Heart Failure (from the Atherosclerosis Risk In Communities [ARIC] Study). Am J Cardiol 2012; 109(1):105-9.

80. Duffee DF, Shen WK, Smith HC. Suppression of frequent premature ventricular contractions and improvement of left ventricular function in patients with presumed idiopathic dilated cardiomyopathy. Mayo Clin Proc 1998; 73: 430-433.

81. Kanei Y, Friedman M, Ogawa N, Hanon S et al. Frequent premature ventricular complexes originating from the right ventricular outflow tract are associated with left ventricular dysfunction. Ann Noninvasive Electrocardiol 2008; 13: 81-85.

82. Niwano S, Wakisaka Y, Niwano H, Fukaya H et al. Prognostic significance of frequent premature ventricular contractions originating from the ventricular outflow tract in patients with normal left ventricular function. Heart 2009; 95: 1230-1237.

83. Baman TS, Lange DC, Ilg KJ, Gupta SK et al. Relationship between burden of premature ventricular complexes and left ventricular function. Heart Rhythm 2010;7: 865-869.

84. Huizar JF, Kaszala K, Potfay J, Minisi AJ et al. Left Ventricular Systolic Dysfunction 
Induced by Ventricular Ectopy: A Novel Model for Premature Ventricular Contraction-Induced Cardiomyopathy. Circ Arrhythm Electrophysiol 2011; 4:543-549.

85. Spragg DD, Kass DA. Pathobiology of left ventricular dyssynchrony and resynchronization. Prog Cardiovasc Dis 2006; 49: 26 - 41.

86. Yokokawa M, Kim HM, Good E, Crawford E et al. Impact of QRS duration of frequent premature ventricular complexes on the development of cardiomyopathy. Heart Rhythm 2012; 9: $1460-1464$.

87. Olgun H, Yokokawa M, Baman T, Kim HM et al. The role of interpolation in PVCinduced cardiomyopathy. Heart Rhythm 2011; 8(7):1046-1049.

88. Ban J, Park H, Park J, Nagamoto et al. Electrocardiographic and electrophysiological characteristics of premature ventricular complexes associated with left ventricular dysfunction in patients without structural heart disease. Europace 2013; 15(5): 735-741.

89. Del Carpio Munoz F, Syed FF, Noheria A, Cha YM et al. Characteristics of premature ventricular complexes as correlates of reduced left ventricular systolic function: study of the burden, duration, coupling interval, morphology and site of origin of PVCs. J Cardiovasc Electrophysiol 2011; 22(7):791-798.

90. Krittayaphong R, Bhuripanyo K, Punlee K, Kangkagate C et al. Effect of atenolol on symptomatic ventricular arrhythmia without structural heart disease: a randomized placebocontrolled study. Am Heart J 2002; 144:e10.

91. Singh SN, Fletcher RD, Fisher SG, Singh BN et al. Amiodarone in patients with congestive heart failure and asymptomatic ventricular arrhythmia. Survival Trial of Antiarrhythmic Therapy in Congestive Heart Failure. N Engl J Med 1995; 333:77- 82.

92. Torp-Pedersen C, Moller M, Bloch-Thomsen PE et al. Dofetilide in patients with 
congestive heart failure and left ventricular dysfunction. Danish Investigations of Arrhythmia and Mortality on Dofetilide Study Group. N Engl J Med 1999; 341:857- 865.

93. Yarlagadda RK, Iwai S, Stein KM, Markowitz SM et al. Reversal of cardiomyopathy in patients with repetitive monomorphic ventricular ectopy originating from the right ventricular outflow tract. Circulation 2005; 112:1092-1097.

94. Bogun F, Crawford T, Reich S, Koelling TM et al. Radiofrequency ablation of frequent, idiopathic premature ventricular complexes: comparison with a control group without intervention. Heart Rhythm 2007; 4: 863- 867.

95. Taieb JM, Maury P, Shah D, Duparc A et al. Reversal of dilated cardiomyopathy by the elimination of frequent left or right premature ventricular contractions. J Interv Card Electrophysiol 2007; 20: 9-13.

96. Wijnmaalen AP, Delgado V, Schalij MJ, van Huls van Taxis CF et al. Beneficial effects of catheter ablation on left ventricular and right ventricular function in patients with frequent premature ventricular contractions and preserved ejection fraction. Heart 2010; 96: 1275-1280. 97. Sekiguchi Y, Aonuma K, Yamauchi Y, Obayashi T et al. Chronic hemodynamic effects after radiofrequency catheter ablation of frequent monomorphic ventricular premature beats. $\mathbf{J}$ Cardiovasc Electrophysiol 2005; 16: 1057-106

98. Hasdemir C, Kartal Y, Simsek E et al. Time course of recovery of left ventricular systolic dysfunction in patients with premature ventricular contraction-induced cardiomyopathy. Pacing Clin Electrophysiol. 2013; 36(5):612-617.

99. Dahl P, Danzi S, Klein I. Thyrotoxic cardiac disease. Curr Heart Fail Rep 2008; 5(3):170176.

100. Siu CW, Yeung CY, Lau CP, Kung AW et al. Incidence, clinical characteristics and 
outcome of congestive heart failure as the initial presentation in patients with primary hyperthyroidism. Heart 2007; 93(4):483-487. 


\section{FIGURE LEGENDS}

1. Improvement in left ventricular ejection fraction (LVEF) based on atrial fibrillation (AF) control with ablation in patients with low LVEF. Improvement in LVEF was greater in those patients with AF control after ablation than in those with recurrent $\mathrm{AF}(\mathrm{P}<0.01)$. Reprinted with permission from: Marchlinski FE, Journal of Cardiovascular Electrophysiology Volume 18, Issue 1, pages 9-14, January 2007.

2. Multivariable adjusted cumulative heart failure events during follow up by the presence any VPCs (143 HF events among 739) vs. absence (1201 HF events among 12747) events in a 2-minute ECG strip among ARIC cohort participants free of heart failure and coronary heart disease at study baseline. (Wilcoxon test $\mathrm{P}<0.001$ ). Model adjusted for age, gender, race, study center, education level, diabetes, systolic blood pressure, hypertension medication intake, LDL and HDL cholesterol, BMI, current smoking, former smoking, pack-years of smoking, amount of ethanol use, heart rate, serum $\mathrm{K}+$, serum $\mathrm{Mg}++$.

Reprinted with permission from: Agarwal SK, American Journal of Cardiology Volume 109, Issue 1, pages 105-109, January 2012. 
Figure 1

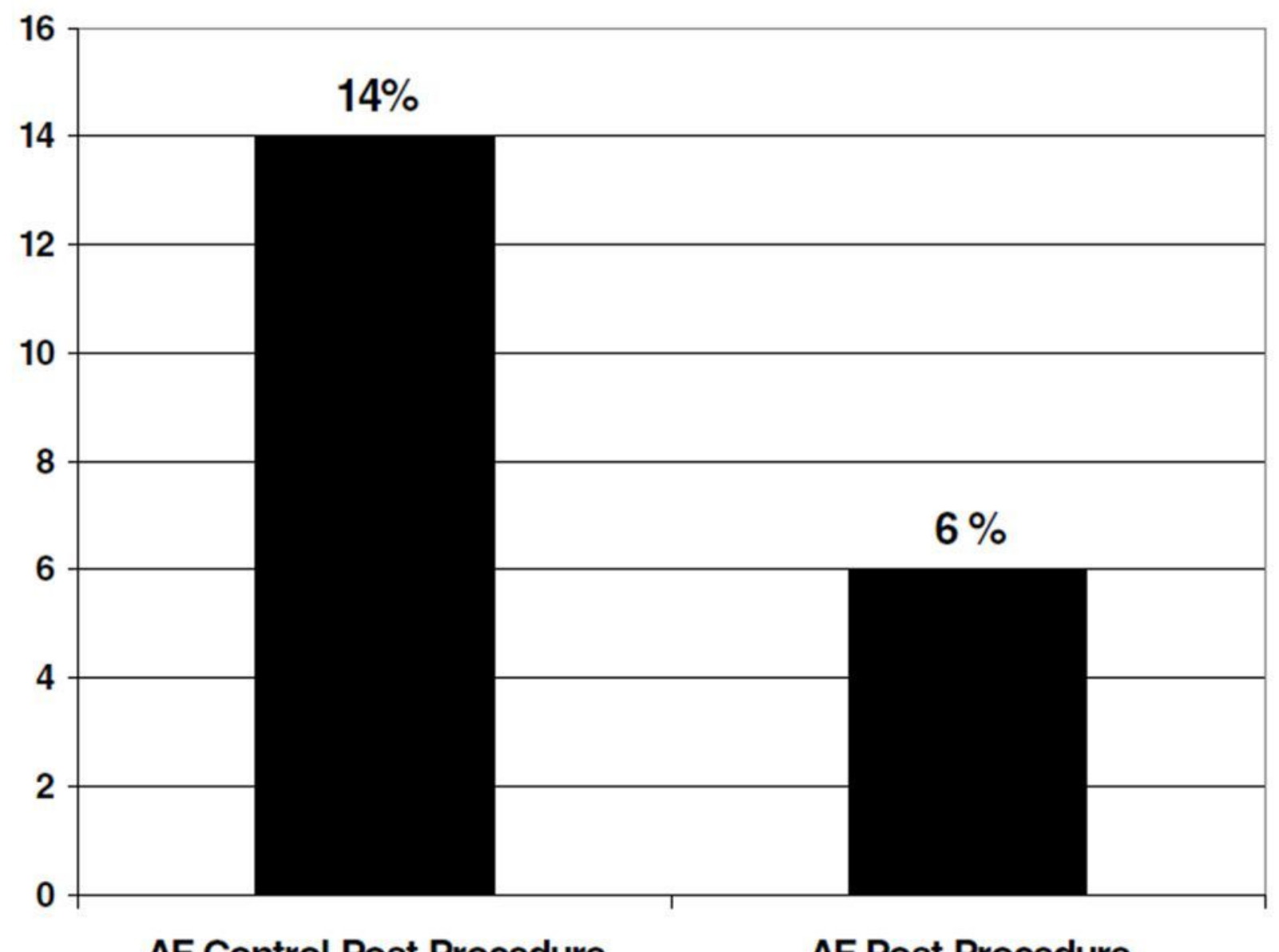

AF Control Post Procedure AF Post Procedure 
Figure 2

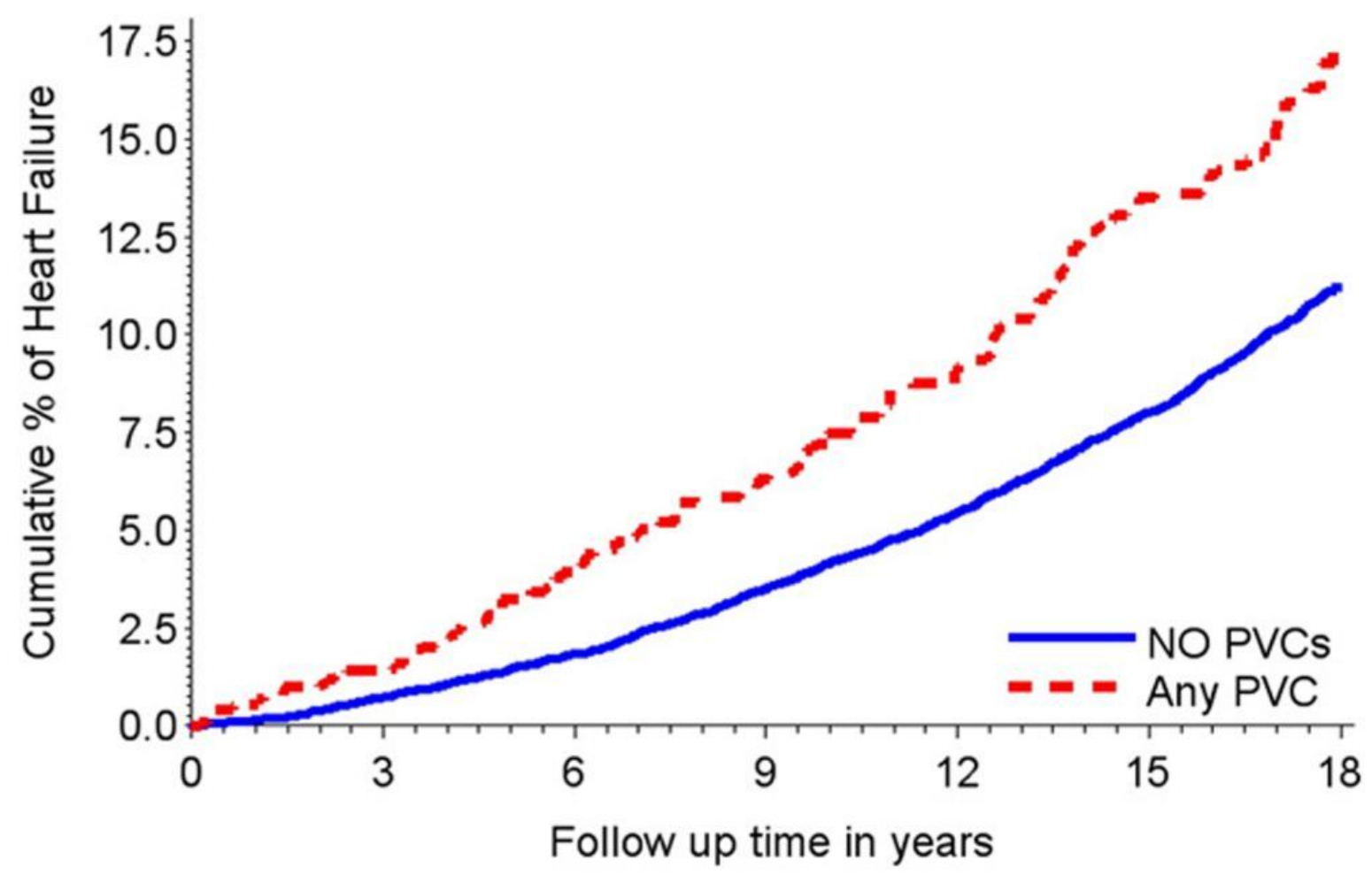


Table 1. Types of Arrhythmias Causing Tachycardia-Mediated Cardiomyopathy

\section{Supraventricular}

- Atrial fibrillation

- Atrial flutter

- Atrial tachycardia

- Permanent junctional reciprocating tachycardia

- AV nodal reentrant tachycardia

- AV reentrant tachycardia

- Inappropriate sinus tachycardia (rare cause)

\section{Ventricular}

- Right ventricular outflow tract ventricular tachycardia

- Fascicular tachycardia

- Bundle branch reentry ventricular tachycardia

\section{Ectopy}

- Premature ventricular complexes

\section{Pacing}

- Persistent rapid ventricular pacing

- High-rate atrial pacing

\section{Other}

- Thyrotoxicosis (sinus tachycardia or atrial fibrillation) 